\title{
The Effect of Participation in Tier 3 Services on the Uptake of Bariatric Surgery
}

\author{
Chanpreet Arhi $^{1}$ (D) Chrysanthi Karagianni $^{1} \cdot$ Louise Howse $^{1} \cdot$ Midhat Siddiqui $^{1} \cdot$ Cynthia-Michelle Borg $^{1}$
}

Received: 9 December 2020 / Revised: 12 February 2021 / Accepted: 12 February 2021 / Published online: 16 March 2021

(C) The Author(s), under exclusive licence to Springer Science+Business Media, LLC part of Springer Nature 2021

\begin{abstract}
Background Despite the recognised advantages of bariatric and metabolic surgery, only a small proportion of patients receive this intervention. In the UK, weight management systems are divided into four tiers. Tier 3 is a clinician-lead weight loss service while tier 4 considers surgery. While there is little evidence that tier 3 has any long-term benefits for weight loss, this study aims to determine whether tier 3 improves the uptake of surgery.

Method A retrospective cohort study of all referrals to our unit between 2013 and 2016 was categorised according to source - tier 3 , directly from the general practitioner (GP) or from another speciality. The likelihood of surgery was calculated using a regression model after considering patient demographics, comorbidities and distance from our hospital.

Results Of the 399 patients, $69.2 \%$ were referred directly from the GP, $21.3 \%$ from tier 3, and $9.5 \%$ from another speciality of which $69.4 \%, 56.2 \%$, and $36.8 \%$ progressed to surgery $(p=0.01)$. On regression analysis, patients from another speciality or GP were more likely to decide against surgery (OR 2.44 CI 1.13-6.80 $p=0.03$ and OR 1.65 CI 1.10-3.12 $p=0.04$ respectively) and more likely to be deemed not suitable for surgery by the MDT (OR 6.42 CI 1.25-33.1 $p=0.02$ and OR 3.47 CI 1.11-12.9 $p=$ 0.03 ) compared with tier 3 referrals.

Conclusion As patients from tier 3 were more likely to undergo bariatric and metabolic surgery, this intervention remains a relevant step in the pathway. Such patients are likely to be better informed about the benefits of surgery and risks of severe obesity.
\end{abstract}

Keywords Weight management services $\cdot$ Tier $3 \cdot$ Surgery

\section{Introduction}

Obesity is a major economic burden in the UK, costing $£ 6.1$ billion to the NHS between 2014 and 2015 [1]. It is associated with a number of medical conditions and is now considered the second highest risk factor for cancer in the UK, behind smoking [2]. The prevalence of obesity is set to increase further, with a predicted 35\% of the population in England suffering from obesity by 2030 , a rise from $27 \%$ in 2015 [3]. In addition, the COVID-19 pandemic has highlighted obesity as a major risk factor for COVID-related hospital admission and death [4], making it a target for recent health policy initiatives [5].

Presented: British Obesity \& Metabolic Surgery Society Conference 2020

Cynthia-Michelle Borg

cynthia.borg@nhs.net

1 Lewisham and Greenwich NHS Trust, University Hospital Lewisham, Lewisham High Street, London SE18 4QH, UK
Although bariatric surgery is considered to be the most effective treatment for severe obesity and its associated conditions [6,7], it is estimated that in the UK, only $0.002 \%$ of eligible patients received this intervention in 2014 [8]. NICE guidance from the same year concluded that patients could be considered for bariatric surgery if their BMI was $\geq 40 \mathrm{~kg} / \mathrm{m}^{2}$ or $\geq 35 \mathrm{~kg} / \mathrm{m}^{2}$ with a comorbidity that could improve with weight loss. This same guidance also described the tier system of weight management services: Tier 1 covers population-level services such as national health promotion, tier 2 includes intervention by the primary care physician, tier 3 is a tailored programme led by a team specialising in weight management (usually constitutes physicians, nurses, dieticians and psychologists, although this varies across the country) and tier 4 is the multidisciplinary team (MDT) that offers bariatric surgery [9]. A patient should only be considered for surgery once they have completed a tier 3 programme [10], entry into which must be requested by the primary care physician. It was expected that this process would filter out patients who did not require surgery, while optimising those who do. 
Studies into tier 3 services provide conflicting reports on their effectiveness [11]. Weight loss during this period does not reliably equate to improved weight loss after surgery [12]. Unfortunately, the majority of patients regain weight by 6 months [13], questioning whether tier 3 programmes should be any longer than this. More recently, the provision of tier 3 services has been taken over by Clinical Commissioning Groups (CCG), so the design of such services varies according to location [14].

Although the evidence for tier 3 services as an aid for preoperative weight loss may be weak, alternative benefits have not been well researched, such as improved conversion rate to surgery. Studies have demonstrated higher deprivation, older age and female gender are associated with increased likelihood to miss hospital appointments [15]. The aim of this study is to determine whether these factors, along with tier 3 involvement, influence the proportion of patients who progress to bariatric surgery.

\section{Method}

\section{Study Design and Population}

This study used a retrospective cohort design with a population consisting of all patients referred between 2013 and 2016 to our tertiary bariatric centre situated in the UK. The unit was established in 2013 and is based in an area of relatively high socioeconomic deprivation. As the NICE criteria regarding tier 4 were introduced in 2014 [10], during the study period, patients would have been referred from three possible sources: Tier 3 services, directly from the patient's general practitioner (GP) or from another specialist (AS) within the trust, for example from orthopaedics or endocrine physicians. Patients referred from the latter two sources would be reviewed by our MDT with the aim to manage comorbidities and psychological issues that would aid preoperative and postoperative weight loss.

\section{Patient Variables and Outcomes}

Data was collected prospectively for all referrals, with outcomes updated as patients progressed through the bariatric pathway. Independent variables included gender, age, initial BMI, referral source and distance from home to our base hospital. Comorbidities included type 2 diabetes, ischaemic heart disease, hypertension, hypercholesterolemia, psychiatric history, asthma and obstructive sleep apnoea (OSA). Socioeconomic status was derived from the Indices of Multiple Deprivation (IMD; 2010) [16], categorised into tertiles (least, middle and most deprivation). Smoking history was also recorded.
The three outcomes from the bariatric pathway were surgery, patient deemed not suitable for surgery by the MDT or patient's decision to leave the pathway. The latter included those that informed the department of their decision and those who failed to attend appointments.

\section{Statistical Analysis}

Univariate analysis using a chi-squared statistical test for categorical data compared the abovementioned factors (patient characteristics and comorbidities) between the sources of referrals. A similar analysis was carried out to describe how the three possible outcomes varied according to these factors. The Kruskal-Wallis test was used to compare medians while analysis of variance compared mean values. A generalised multinomial regression model described the characteristics most likely to lead to surgery as the dependent reference category (primary outcome), after taking into account all covariates (secondary outcomes) with a $p<0.1$ significance on univariate analysis. Analysis was carried out with SPSS v26.

\section{Results}

Between 2013 and 2016, 484 patients were referred to our bariatric unit. After including only patients with a BMI of over $35 \mathrm{~kg} / \mathrm{m}^{2}$ with an obesity-related comorbidity or BMI over 40 $\mathrm{kg} / \mathrm{m}^{2}$, and excluding those with missing data or previous bariatric surgery, $399(82.5 \%)$ patients formed the basis for analysis (Fig. 1). Overall, 297 (74.4\%) were female, with an average age of 45.1 years (95\% CI 44.0-46.3) and initial median BMI of $47.2 \mathrm{~kg} / \mathrm{m}^{2}$ (IQR 42.9-52.9). Two hundred forty-seven patients $(61.9 \%)$ were from the most deprived areas, $124(31.1 \%)$ from the middle tercile with the remaining $28(7.0 \%)$ from the least deprived areas. The majority of patients were referred directly from the GP $(n=276,69.2 \%)$, followed by referral from a tier 3 service $(n=85,21.3 \%)$ and from another speciality $(n=38,9.5 \%)$. After embarking on the bariatric pathway, 228 (57.1\%) underwent surgery, 41 $(10.3 \%)$ were deemed not fit for surgery at the time of the MDT meeting, with the remaining 130 (32.6\%) opting not to undergo surgery.

The average age for the AS group (50.2 years $95 \%$ CI 45.8-54.7) was significantly higher than both the GP (44.7 years $95 \%$ CI $43.3-46.1)$ and tier 3 (44.3 years 95\% CI 41.7-46.8) groups $(p=0.04)$. Patients from tier 3 included the highest proportion of BMI $50 \mathrm{~kg} / \mathrm{m}^{2}$ and over (45.9\%), compared with $35.1 \%$ from GPs and $31.6 \%$ from other specialties. The proportion of female patients was similar across the groups. Although the vast majority of tier 3 patients were from within $10 \mathrm{~km}$ from our base hospital (92.9\%), this group also included the highest proportion of patients who lived over $50 \mathrm{~km}$ away (5.9\%) (Table 1). 
Fig. 1 Flowchart showing the numbers excluded. Percentages of original 484 patients

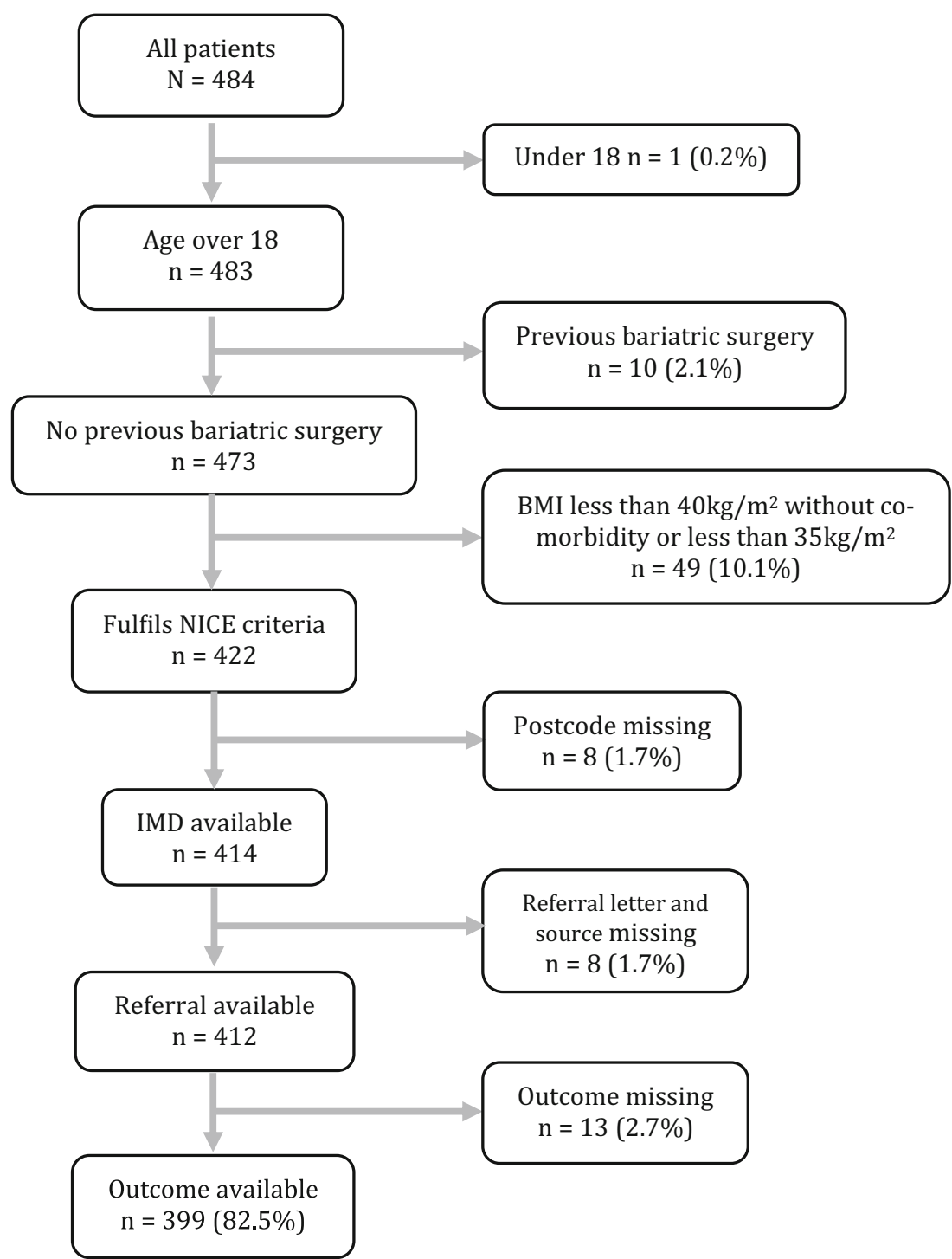

Of those referred from AS, $47.4 \%(n=18)$ suffered from type 2 diabetes. This was significantly higher than both tier 3 $(34.1 \% n=29)$ and GP referrals $(27.9 \% n=77)(p=0.04)$ (Table 1). The AS group also included the highest proportion of patients suffering from osteoarthritis $(42.1 \% n=16, p=$ $0.02)$, previous cerebrovascular event $(10.5 \% n=4, p=0.04)$ and CKD $(10.5 \% n=4, p=0.03)$. Both GP and tier 3 referrals had similar proportion of patients who were on medication for depression $(19.2 \%(n=53)$ and $12.9 \%(n=11)$ respectively), which were significantly lower than those in AS $(26.3 \% n=$ 10) $(p=0.04)$. Tier 3 patients had the highest proportion of vitamin $\mathrm{D}$ deficiency $(43.5 \% n=37, p=0.01)$. Patients referred from GPs were more likely to have undergone a previous abdominal operation $(44.9 \% n=124)$, with the lowest in the AS group $(21.1 \% n=8)$. There was no difference in the IMD between the three groups, or the other comorbidities listed in Table 1 including hypertension and obstructive sleep apnoea. There was a higher proportion of patients suffering from PCOS in the tier 3 service $(16.2 \% n=11)$, although this did not reach significance (Table 1).

Of those who had participated in a tier 3 service, 59 $(69.4 \%)$ progressed to an operation compared with 155 $(56.2 \%)$ referred from the GP and $14(36.8 \%)$ referred in house (AS group) ( $p=0.01)$ (Table 2). The group with the highest proportion of patients deemed not suitable for surgery when discussed in the MDT was from the AS group $(21.1 \% n$ $=8)$, followed by patients from the GPs $(n=3010.9 \%)$ and then tier $3(3.5 \% n=3) .42 .1 \%(n=16)$ patients from AS group decided against surgery, compared with $33.0 \%(n=91)$ of the GP referral group $(32.6 \% n=91)$ and $27.1 \%(n=23)$ from tier 3 . The mean age was significantly lower for patients who underwent surgery (43.9 years) compared with those refused by the MDT (50.2 years) or if the patient refused (45.7 years). A higher proportion of females $(60.6 \%)$ went ahead with surgery compared with males $(47.1 \%)$, while a history of CVA or IHD was associated with a higher percentage of 
Table 1 Patient demographics and comorbidities according to referral group. Figures are $n$ (\% of group) unless stated. $A S$, another speciality; $G P$, general practitioner; $I M D$, Index of Multilevel Deprivation

\begin{tabular}{|c|c|c|c|c|c|c|}
\hline & & All $N=399$ & Tier $3 n=85$ & GP $n=276$ & AS $n=38$ & $p$ \\
\hline \multirow[t]{3}{*}{ Body mass index $\mathrm{kg} / \mathrm{m}^{2}$} & $35-39.9$ & $40(10.0)$ & $3(3.5)$ & $28(10.1)$ & $9(23.7)$ & \multirow[t]{3}{*}{0.01} \\
\hline & $40-49.9$ & $211(52.9)$ & $43(50.6)$ & $151(54.7)$ & $17(44.7)$ & \\
\hline & 50 and over & $148(37.1)$ & $39(45.9)$ & $97(35.1)$ & $12(31.6)$ & \\
\hline \multicolumn{2}{|l|}{ Mean age, years $(95 \% \mathrm{CI})$} & $45.1(44.0-46.3)$ & $44.3(41.7-46.8)$ & $44.7(43.3-46.1)$ & $50.2(45.8-54.7)$ & 0.04 \\
\hline \multirow[t]{2}{*}{ Gender } & Female & $297(74.4)$ & $68(80.0)$ & $207(75)$ & $22(57.9)$ & \multirow[t]{2}{*}{0.03} \\
\hline & Male & $102(25.6)$ & $17(20)$ & $69(25)$ & $16(42.1)$ & \\
\hline \multirow[t]{3}{*}{ IMD tercile } & Most & 247 (61.9) & $46(54.1)$ & $178(64.5)$ & $23(60.5)$ & \multirow[t]{3}{*}{0.52} \\
\hline & Middle & $124(31.1)$ & $31(36.5)$ & $81(29.3)$ & $12(31.6)$ & \\
\hline & Least & $28(7.0)$ & $8(9.4)$ & $12(1.6)$ & $3(7.9)$ & \\
\hline \multirow[t]{4}{*}{ Distance from base hospital, $\mathrm{km}$} & $0-10$ & $275(69.1)$ & $79(92.9)$ & $175(63.4)$ & $21(56.8)$ & \multirow[t]{4}{*}{$<0.005$} \\
\hline & $10-20$ & $105(26.4)$ & $1(1.2)$ & $88(31.9)$ & $16(43.2)$ & \\
\hline & $20-50$ & $10(2.5)$ & - & $10(3.6)$ & - & \\
\hline & 50 and over & $8(2.0)$ & $5(5.9)$ & $3(1.1)$ & - & \\
\hline \multirow[t]{3}{*}{ Smoking history } & Never & $261(65.4)$ & $48(56.5)$ & $185(67.0)$ & $28(73.7)$ & \multirow[t]{3}{*}{0.04} \\
\hline & Stopped & $68(17.0)$ & $18(21.2)$ & $44(15.9)$ & $6(15.8)$ & \\
\hline & Current & $70(70.5)$ & $19(22.4)$ & $47(17.0)$ & $4(10.5)$ & \\
\hline \multicolumn{7}{|l|}{ Comorbidities } \\
\hline \multirow[t]{2}{*}{ Type II diabetes } & Yes & $124(31.1)$ & $29(34.1)$ & $77(27.9)$ & $18(47.4)$ & \multirow[t]{2}{*}{0.04} \\
\hline & No & 275 (68.9) & $56(65.9)$ & $199(72.1)$ & $20(52.6)$ & \\
\hline \multirow[t]{2}{*}{ Hypertension } & Yes & $161(40.4)$ & $29(34.1)$ & $111(40.2)$ & $21(55.3)$ & \multirow[t]{2}{*}{0.09} \\
\hline & No & $238(59.6)$ & $56(65.9)$ & $165(59.8)$ & $17(44.7)$ & \\
\hline \multirow[t]{2}{*}{ Hypercholesterolemia } & Yes & $124(31.1)$ & $27(31.8)$ & $87(31.5)$ & $10(26.3)$ & \multirow[t]{2}{*}{0.80} \\
\hline & No & $275(68.1)$ & $58(68.2)$ & $189(68.5)$ & $28(73.7)$ & \\
\hline \multirow[t]{2}{*}{ Obstructive sleep apnea } & Yes & $84(21.1)$ & $19(22.4)$ & $55(19.9)$ & $10(26.3)$ & \multirow[t]{2}{*}{0.63} \\
\hline & No & 315 (78.9) & $66(77.6)$ & $221(80.1)$ & $28(73.7)$ & \\
\hline \multirow[t]{2}{*}{ Chronic obstructive pulmonary disease } & Yes & $14(3.5)$ & $4(4.7)$ & $9(3.3)$ & $1(2.6)$ & 0.78 \\
\hline & No & $385(96.5)$ & $81(95.3)$ & $267(96.7)$ & $37(97.4)$ & \\
\hline Asthma & Yes & $67(16.8)$ & $9(10.6)$ & $53(19.2)$ & $5(13.2)$ & 0.15 \\
\hline & No & $332(83.2)$ & $76(89.4)$ & $223(80.8)$ & $33(86.8)$ & \\
\hline Osteoarthritis & Yes & $103(25.8)$ & $15(17.6)$ & $72(26.1)$ & $16(42.1)$ & 0.02 \\
\hline & No & $296(74.2)$ & $70(82.4)$ & $204(73.9)$ & $22(57.9)$ & \\
\hline Polycystic ovarian disease (fem only) & Yes & $38(12.8)$ & $11(16.2)$ & $25(12.2)$ & $2(9.1)$ & 0.59 \\
\hline & No & $269(87.2)$ & $57(83.8)$ & $182(87.9)$ & $20(90.9)$ & \\
\hline Gastroesophageal reflux disease & On PPI & $61(15.3)$ & $7(8.2)$ & $48(17.4)$ & $6(15.8)$ & 0.28 \\
\hline & Yes but not on PPI & $55(13.8)$ & $11(12.9)$ & $40(14.5)$ & $4(10.5)$ & \\
\hline & Never & $283(70.9)$ & $67(78.8)$ & $188(68.1)$ & $28(73.7)$ & \\
\hline Cerebrovascular accident & Yes & $15(3.8)$ & $1(1.2)$ & $10(3.6)$ & $4(10.5)$ & 0.04 \\
\hline & No & $384(96.2)$ & $84(98.8)$ & $266(96.4)$ & $34(89.5)$ & \\
\hline Ischaemic heart disease & Yes & $20(5.0)$ & $3(3.5)$ & $13(4.7)$ & $4(10.5)$ & 0.24 \\
\hline & No & $379(95.0)$ & $82(86.5)$ & $263(95.3)$ & $34(89.5)$ & \\
\hline Chronic kidney disease & Yes & $14(3.5)$ & $1(1.2)$ & $9(3.3)$ & $4(10.5)$ & 0.03 \\
\hline & No & $385(96.5)$ & $84(98.8)$ & $267(96.7)$ & $34(89.5)$ & \\
\hline Vitamin D deficiency & Yes & $131(32.8)$ & $37(43.5)$ & $88(31.9)$ & $6(15.8)$ & 0.01 \\
\hline & No & $268(67.2)$ & $48(56.5)$ & $188(61.9)$ & $32(84.2)$ & \\
\hline Previous surgery & Yes & $165(41.4)$ & $33(38.8)$ & $124(44.9)$ & $8(21.1)$ & 0.02 \\
\hline & No & $234(58.6)$ & $52(61.2)$ & $152(55.1)$ & $30(78.9)$ & \\
\hline Depression & No & $245(61.4)$ & $56(65.9)$ & $163(59.1)$ & $26(68.4)$ & 0.04 \\
\hline & Yes without medication & $74(18.5)$ & $11(12.9)$ & $53(19.2)$ & $10(26.3)$ & \\
\hline & On medication & $80(20.1)$ & $18(21.2)$ & $10(26.3)$ & $2(5.3)$ & \\
\hline
\end{tabular}


Table 2 Outcome according to patient demographics and comorbidities. Figures are $n$ (\% of group) unless stated. MDT, multidisciplinary team; $\mathrm{km}$, kilometres; IMD, Index of Multilevel Deprivation

\begin{tabular}{|c|c|c|c|c|c|}
\hline & & Surgery & Refused by MDT & Patient refused & $p$ \\
\hline \multirow[t]{3}{*}{ Source of referral } & Tier 3 & $59(69.4)$ & $3(3.5)$ & $23(27.1)$ & \multirow[t]{3}{*}{0.01} \\
\hline & GP & $155(56.2)$ & $30(10.9)$ & $91(33.0)$ & \\
\hline & AS & $14(36.8)$ & $8(21.1)$ & $16(42.1)$ & \\
\hline \multirow[t]{3}{*}{ Body mass index $\mathrm{kg} / \mathrm{m}^{2}$} & $35-39.9$ & $25(62.5)$ & $6(15.0)$ & $9(22.5)$ & \multirow[t]{3}{*}{0.37} \\
\hline & $40-49.9$ & $123(58.7)$ & $17(8.1)$ & $71(33.6)$ & \\
\hline & 50 and over & $80(54.1)$ & $18(12.2)$ & $50(33.8)$ & \\
\hline \multicolumn{2}{|l|}{ Mean age, years $(95 \% \mathrm{CI})$} & $43.9(42.5-45.4)$ & $50.2(46.2-54.2)$ & $45.7(43.4-47.9)$ & 0.01 \\
\hline \multirow[t]{2}{*}{ Gender } & Female & $180(60.6)$ & $31(10.4)$ & $86(29.0)$ & \multirow[t]{2}{*}{0.03} \\
\hline & Male & $48(47.1)$ & $10(9.8)$ & $44(43.1)$ & \\
\hline \multirow[t]{3}{*}{ IMD tertile } & Most & $132(53.4)$ & $28(11.3)$ & $87(35.2)$ & \multirow[t]{3}{*}{0.38} \\
\hline & Middle & $80(64.5)$ & $10(8.1)$ & $34(27.4)$ & \\
\hline & Least & $16(57.1)$ & $3(10.7)$ & $9(32.1)$ & \\
\hline \multirow[t]{4}{*}{ Distance from base hospital, $\mathrm{km}$} & $0-10$ & $147(53.5)$ & $28(10.2)$ & $100(36.4)$ & \multirow[t]{4}{*}{0.08} \\
\hline & $10-20$ & $69(65.7)$ & $10(9.5)$ & $26(24.8)$ & \\
\hline & $20-50$ & $6(60.0)$ & $3(30.0)$ & $1(10.0)$ & \\
\hline & 50 and over & $5(62.5)$ & $0(0.0)$ & $3(37.5)$ & \\
\hline \multirow[t]{3}{*}{ Smoking history } & Never & $139(53.3)$ & $23(8.8)$ & $99(37.9)$ & \multirow[t]{3}{*}{0.03} \\
\hline & Stopped & $44(64.7)$ & $8(11.8)$ & $16(23.5)$ & \\
\hline & Current & $45(64.3)$ & $10(14.3)$ & $15(21.4)$ & \\
\hline \multirow[t]{2}{*}{ Type II diabetes } & Yes & $62(50.0)$ & $19(15.3)$ & $43(34.7)$ & \multirow[t]{2}{*}{0.04} \\
\hline & No & $166(60.4)$ & $22(8.0)$ & 87 (31.6) & \\
\hline \multirow[t]{2}{*}{ Hypertension } & Yes & $87(54.0)$ & $23(14.3)$ & $51(31.7)$ & \multirow[t]{2}{*}{0.09} \\
\hline & No & $141(59.2)$ & $18(7.6)$ & $79(33.2)$ & \\
\hline \multirow[t]{2}{*}{ Hypercholesterolemia } & Yes & $74(59.7)$ & $15(12.1)$ & $35(28.2)$ & \multirow[t]{2}{*}{0.40} \\
\hline & No & $154(56.0)$ & $26(9.5)$ & $95(34.5)$ & \\
\hline \multirow[t]{2}{*}{ Obstructive sleep apnea } & Yes & $50(59.5)$ & $16(19.0)$ & $18(21.4)$ & $<0.005$ \\
\hline & No & $178(56.5)$ & $25(7.9)$ & $112(35.6)$ & \\
\hline Chronic obstructive pulmonary disease & Yes & $4(28.6)$ & $4(28.6)$ & $6(42.9)$ & 0.03 \\
\hline & No & $224(58.2)$ & $37(9.6)$ & $124(32.2)$ & \\
\hline Asthma & Yes & $36(53.7)$ & $8(11.9)$ & $23(34.3)$ & 0.80 \\
\hline & No & $192(57.8)$ & $33(9.9)$ & $107(32.2)$ & \\
\hline Osteoarthritis & Yes & $56(54.4)$ & $19(18.4)$ & $28(27.2)$ & 0.01 \\
\hline & No & $172(58.1)$ & $22(7.4)$ & $102(34.5)$ & \\
\hline Polycystic ovarian disease (fem only) & Yes & $27(71.1)$ & $4(10.5)$ & $7(18.4)$ & 0.29 \\
\hline & No & $153(59.1)$ & $27(10.4)$ & $79(30.5)$ & \\
\hline Gastroesophageal reflux disease & On PPI & $27(44.3)$ & $15(24.6)$ & $19(31.1)$ & $<0.005$ \\
\hline & Yes but not on PPI & $44(80.0)$ & $5(9.1)$ & $6(10.9)$ & \\
\hline & Never & $157(55.5)$ & $21(7.4)$ & $105(37.1)$ & \\
\hline Cerebrovascular accident & Yes & $4(26.7)$ & $7(46.7)$ & $4(26.7)$ & $<0.005$ \\
\hline & No & $224(58.3)$ & $34(8.9)$ & $126(32.8)$ & \\
\hline Ischaemic heart disease & Yes & $6(30.0)$ & $7(35.0)$ & $7(35.0)$ & $<0.005$ \\
\hline & No & $222(58.6)$ & $34(9.0)$ & $123(32.5)$ & \\
\hline Chronic kidney disease & Yes & $6(42.9)$ & $4(28.6)$ & $4(28.6)$ & 0.07 \\
\hline & No & $222(57.7)$ & $37(9.6)$ & $126(32.7)$ & \\
\hline Vitamin D deficiency & Yes & $94(71.8)$ & $11(8.4)$ & $26(19.8)$ & $<0.005$ \\
\hline & No & $134(50.0)$ & $30(11.2)$ & $104(38.8)$ & \\
\hline Previous surgery & Yes & $115(69.7)$ & $18(10.9)$ & $32(19.4)$ & $<0.005$ \\
\hline & No & $113(48.3)$ & $23(9.8)$ & $98(41.9)$ & \\
\hline Depression & No & $132(53.9)$ & $19(7.8)$ & $94(38.4)$ & 0.01 \\
\hline & Yes without medication & $42(56.8)$ & $10(13.5)$ & $22(29.7)$ & \\
\hline & On medication & $54(67.5)$ & $12(15.0)$ & $14(17.5)$ & \\
\hline
\end{tabular}


patients being refused surgery by the MDT. There was no statistical significance in outcome for BMI, distance from our hospital, level of deprivation, hypertension, hypercholesterolemia, CKD, PCOS.

On regression analysis, patients from AS or GP were more likely to decide against surgery (OR $2.4495 \% \mathrm{CI}$ 1.13-6.80 $p=0.03$ and OR $1.6595 \%$ CI $1.10-3.12 p=$ 0.04 ) and more likely to be deemed not suitable for surgery by the MDT (OR 6.42 95\% CI 1.25-33.1 $p=$ 0.02 and OR $3.4795 \%$ CI $1.11-12.9 p=0.03$ ) compared with those referred from tier 3. A BMI of over 50 was more likely to lead to a patient refusing surgery (OR 3.14 95\% CI 1.19-8.28 $p=0.02$ ). Patients with a vitamin D deficiency (OR $0.3795 \%$ CI $0.21-0.66 p<$ 0.005 ) or previous abdominal surgery (OR $0.3895 \% \mathrm{CI}$ $0.22-0.67 p<0.005$ ) were less likely to decide against surgery. There was no association between the other comorbidities, age, gender, IMD, smoking history or distance from base hospital and the failure to proceed to surgery between the three groups (Table 3).

\section{Discussion}

The provision of bariatric and metabolic surgery in the UK remains poor. The aim of this study was to determine the factors that could improve the uptake of this intervention, in the wake of a worsening obesity pandemic. Our study demonstrates that a tier 3 programme reduced the drop-out rate and so patients were more likely to progress to surgery in tier 4, even after taking into consideration comorbidities, demographics and distance from the hospital, compared to those referred directly from their GP or other specialities. Of note, higher levels of socioeconomic deprivation made no significant difference in the likelihood of surgery. This study improves our understanding of the barriers to bariatric surgery and suggests there may be a role of the tier 3 service in preparing patients for this intervention.

This study includes patients from when our unit was first opened in 2013, which predates the 2014 NICE guidelines mandating the requirement for tier 3 intervention [10]. As a result, there is a relatively high proportion of patients in the GP group, a figure that has reduced in recent years (data not provided). Subsequently, this study gives an insight into the benefits of tier 3 services.

In a recent systematic review, Alkharaiji et al. [13] demonstrated that $39.2 \%$ of tier 3 participants demonstrated $\geq 5 \%$ weight loss by 6 months, which increased marginally to $43.4 \%$ at 12 months. Although there was also an improvement in the obesity-related comorbidities, $33.4 \%$ of patients had dropped out by 6 months, increasing to $44.1 \%$ by the end of the first year. These findings confirmed the earlier systematic review by Brown et al. [17] who also showed that using low- calorie diets made the most significant difference to weight loss in the tier 3 setting. Neither of these reviews considered whether the weight loss or participation in a tier 3 programme improved the uptake of surgery in tier 4 .

In a review of the current NHS England policy on obesity services, Hazlehurst et al. [11] concluded that tier 3 services would not reduce the proportion of patients seeking bariatric surgery as the modest weight loss in tier 3 is unlikely to meet a patient's expectations when they seek weight reduction interventions. Although a number of studies have demonstrated that weight loss in tier 3 does not necessarily correspond to better weight loss after bariatric surgery $[12,18]$, to our knowledge, there are no studies which have investigated the benefit of tier 3 services in improving surgery uptake. As demonstrated in our study, tier 3 services seemed to reduce the drop-out rate from 33 to $27 \%$ when compared to those that are referred directly from the GP. Essentially, the GP group represents patients who are at the beginning of their bariatric pathway, and so differ from tier 3 patients, who should be more informed about the risks of obesity and benefits and possible complications associated with surgery. This correlates with the finding that patients referred by other specialities were least likely to undergo surgery - they would have been referred for an obesityrelated comorbidity, such as osteoarthritis, and so were not initially considering bariatric surgery. In addition, patients from this group were also most likely to be refused surgery, reflecting the higher levels of comorbidities seen in this group.

Higher levels of deprivation, extreme age, and female gender are known to be associated with worse non-attendance rates to outpatient clinics [15]. Although this may be the case with stand-alone clinics, our findings demonstrate this is not a significant bearing on patients on the bariatric pathway. The latter is a longer, more involved process that requires building a relationship between the patient and the bariatric team. Interestingly, patients with a BMI of over $50 \mathrm{~kg} / \mathrm{m}^{2}$ were more likely to refuse surgery. This may be due to the higher perceived risk associated with such BMIs, although we were unable to elucidate the reasons in this study.

In essence, the findings of our study should be used to support the principles of tier 3, rather than accepting the current structure of obesity service. Our opinion aligns with that of Hazlehurst et al. [11] in that pre-tier 4 services should be more efficient in identifying and preparing patients who wish to proceed to surgery rather than insisting on barriers to surgery such as a certain time or percentage weight loss during the tier 3 programme. During this period, patients' expectations of surgery can be managed [19], with realistic goals outlined. In countries that do not follow such a formalised system, this study highlights the importance of programmes that aim to prepare and educate patients before surgery. 
Table 3 Odd ratio (OR) of a patient characteristic or comorbidity being associated with the patient refusing surgery or not being suitable for surgery as deemed by the MDT compared with those who underwent surgery. $A S$, another speciality; $G P$, general practitioner

\begin{tabular}{|c|c|c|c|c|c|}
\hline & & \multicolumn{2}{|c|}{ Not suitable by MDT } & \multicolumn{2}{|l|}{ Patient refused } \\
\hline & & OR & $p$ & OR & $p$ \\
\hline \multicolumn{2}{|l|}{ Age } & $1.02(0.98-1.06)$ & 0.38 & $1.01(0.99-1.04)$ & 0.44 \\
\hline \multicolumn{2}{|l|}{ Distance from base hospital } & $1.00(0.96-1.03)$ & 0.78 & $0.99(0.97-1.01)$ & 0.46 \\
\hline \multirow[t]{3}{*}{ Body mass index } & 50 and over & $0.86(0.24-3.10)$ & 0.81 & $3.14(1.19-8.28)$ & 0.02 \\
\hline & $40-49.9$ & $0.50(0.15-1.70)$ & 0.27 & $2.33(0.93-5.87)$ & 0.07 \\
\hline & $35-39.9$ & Ref & & Ref & \\
\hline \multirow[t]{2}{*}{ Gender } & Female & $1.62(0.56-4.67)$ & 0.37 & $0.59(0.31-1.10)$ & 0.10 \\
\hline & Male & Ref & & Ref & \\
\hline \multirow[t]{3}{*}{ Source of referral } & AS & $6.42(1.25-33.1)$ & 0.02 & $2.44(1.13-6.80)$ & 0.03 \\
\hline & GP & $3.47(1.11-12.9)$ & 0.03 & $1.65(1.10-3.12)$ & 0.04 \\
\hline & Tier 3 & Ref & & Ref & \\
\hline \multirow[t]{3}{*}{ Smoking history } & Current & $1.78(0.64-4.95)$ & 0.27 & $0.72(0.34-1.52)$ & 0.39 \\
\hline & Ex-smoker & $1.03(0.36-2.95)$ & 0.96 & $0.57(0.27-1.19)$ & 0.13 \\
\hline & No & Ref & & Ref & \\
\hline \multirow[t]{2}{*}{ Type II DM } & Yes & $1.62(0.69-3.81)$ & 0.27 & $1.36(0.76-2.44)$ & 0.30 \\
\hline & No & Ref & & Ref & \\
\hline \multirow[t]{2}{*}{ Hypertension } & Yes & $0.99(0.40-2.43)$ & 0.98 & $0.81(0.45-1.43)$ & 0.46 \\
\hline & No & Ref & & Ref & \\
\hline \multirow[t]{2}{*}{ Chronic obstructive pulmonary disease } & Yes & $1.42(0.19-10.7)$ & 0.73 & $7.13(1.37-37.1)$ & 0.02 \\
\hline & No & Ref & & Ref & \\
\hline \multirow[t]{2}{*}{ Obstructive sleep apnea } & Yes & $1.69(0.65-4.35)$ & 0.28 & $0.28(0.13-0.59)$ & $<0.005$ \\
\hline & No & Ref & & Ref & \\
\hline \multirow[t]{2}{*}{ Osteoarthritis } & Yes & $1.65(0.69-3.94)$ & 0.26 & $0.71(0.37-1.33)$ & 0.28 \\
\hline & No & Ref & & Ref & \\
\hline \multirow[t]{2}{*}{ Cerebrovascular accident } & Yes & $3.43(0.70-16.8)$ & 0.13 & $0.83(0.16-4.30)$ & 0.82 \\
\hline & No & Ref & & Ref & \\
\hline \multirow[t]{2}{*}{ Ischaemic heart disease } & Yes & $3.40(0.73-15.8)$ & 0.12 & $1.79(0.42-7.70)$ & 0.43 \\
\hline & No & Ref & & Ref & \\
\hline \multirow[t]{2}{*}{ Chronic kidney disease } & Yes & $2.95(0.48-18.0)$ & 0.24 & $1.15(0.21-6.41)$ & 0.87 \\
\hline & No & Ref & & Ref & \\
\hline \multirow[t]{3}{*}{ Depression } & On medication & $1.94(0.74-5.09)$ & 0.18 & $0.55(0.26-1.13)$ & 0.10 \\
\hline & Yes without medication & $1.74(0.66-4.61)$ & 0.27 & $0.70(0.36-1.39)$ & 0.31 \\
\hline & No & Ref & & Ref & \\
\hline \multirow[t]{3}{*}{ Gastroesophageal reflux disease } & On PPI & $2.78(1.09-7.22)$ & 0.03 & $1.37(0.65-2.92)$ & 0.41 \\
\hline & Yes but not on PPI & $0.62(0.19-2.01)$ & 0.43 & $0.22(0.09-0.57)$ & $<0.005$ \\
\hline & No & Ref & & Ref & \\
\hline \multirow[t]{2}{*}{ Vitamin D deficiency } & Yes & $0.54(0.23-1.26)$ & 0.16 & $0.37(0.21-0.66)$ & $<0.005$ \\
\hline & No & Ref & & Ref & \\
\hline \multirow[t]{2}{*}{ Previous abdominal surgery } & Yes & $0.51(0.22-1.22)$ & 0.13 & $0.38(0.22-0.67)$ & $<0.005$ \\
\hline & No & Ref & & Ref & \\
\hline
\end{tabular}

\section{Strengths and Limitations}

Despite the retrospective analysis, the data analysed in this study was recorded prospectively as each patient progressed through the bariatric pathway. Due to the robustness of the database, our demographic and comorbidity data was fairly complete, including the outcome.

The findings of this study should be interpreted after considering the following limitations. Although patients failed to attend appointments, and therefore were discharged, it is possible that they underwent surgery elsewhere. However, the number of such patients is expected to be low. In 2017, the department made a concerted effort to call all patients who failed to attend appointments. Although this represents a change in practice over the course of the study period, this intervention was similar despite the source of referral. As the tier 3 service was provided outside of our hospital, by different providers, the duration, heterogenicity of interventions and the drop-out rate were not available for this study. Therefore, the influence on engagement by variation in practice during tier 3 cannot be evaluated. Weight loss was not included in this study, as a primary or secondary outcome, as it was not consistently available. It is possible improved weight loss may have led to a patient deciding that surgery was no longer needed, although this is likely to represent the minority of patients. In addition, this would be expected to impact the number proceeding from tier 3 rather than the other groups. A future prospective study recording the specific reasons patients decide to no longer attend or decide against surgery would further improve our understanding, including the influence of information gathered from fellow patients, possibly from social media. 


\section{Conclusions}

Although bariatric and metabolic surgery has been shown to be the most effective intervention for sustained weight loss and remission of comorbidities, the vast majority of suitable patients in the UK are currently not being offered the opportunity to undergo such procedures. This study adds to our understanding of why patients may decide against bariatric surgery and re-iterates the importance of using tier 3 services as a preparation, rather than a barrier, to surgery.

Authors' Contribution All authors take equal responsibility for the accuracy and integrity of this study. C. A.: Study design, analysis and wrote the manuscript. C. K.: Data collection, analysis and wrote the manuscript. L. H.: Study design, data collection analysis and approved the final draft. M. S.: Study design and approved the final draft. C-M.B.: Study design, data collection, analysis and approved the final draft

\section{Declarations}

Ethics Approval and Consent to Participate Ethical Approval was not required and informed consent was not necessary for this study

Conflict of Interest The authors declare no conflict of interest

\section{References}

1. Public Health England. Health matters: obesity and the food environment. 2017. https://www.gov.uk/government/publications/ health-matters-obesity-and-the-food-environment/health-mattersobesity-and-the-food-environment $\% 2 \mathrm{D} \% 2 \mathrm{D} 2 \#$ scale-of-theobesity-problem. Accessed 20 Nov 2020.

2. Cancer Research UK. Statistics on preventable cancers. n.d.. https:// www.cancerresearchuk.org/health-professional/cancer-statistics/ risk/preventable-cancers. Accessed 20 Nov 2020.

3. OECD/European Observatory on Health Systems and Policies. Obesity Update 2017 2017;13:331-41.

4. Popkin BM, Du S, Green WD, et al. Individuals with obesity and COVID-19: a global perspective on the epidemiology and biological relationships. Obes Rev. 2020;21:1-17. https://doi.org/10. 1111/obr.13128.

5. Department of Health and Social Care. Tackling obesity: empowering adults and children to live healthier lives. 2020. https:/www.gov.uk/government/publications/tackling-obesitygovernment-strategy/tackling-obesity-empowering-adults-andchildren-to-live-healthier-lives. Accessed 20 Nov 2020.

6. Jakobsen GS, Småstuen MC, Sandbu R, et al. Association of bariatric surgery vs medical obesity treatment with long-term medical complications and obesity-related comorbidities. JAMA - J Am
Med Assoc. 2018;319:291-301. https://doi.org/10.1001/jama. 2017.21055

7. Sjöström L. Review of the key results from the Swedish Obese Subjects (SOS) trial - a prospective controlled intervention study of bariatric surgery. J Intern Med. 2013;273:219-34. https://doi. org/10.1111/joim.12012.

8. Desogus D, Menon V, Singhal R, et al. An examination of who is eligible and who is receiving bariatric surgery in England: secondary analysis of the health survey for England dataset. Obes Surg. 2019;29:3246-51. https://doi.org/10.1007/s11695-019-03977-3.

9. Capehorn MS, Haslam DW, Welbourn R. Obesity treatment in the UK health system. Curr Obes Rep. 2016;5:320-6. https://doi.org/ 10.1007/s13679-016-0221-z.

10. National Institute for Health and Care Excellence (NICE). Guidelines nice: obesity: identification , assessment and management. 2014. https://www.nice.org.uk/guidance/cg189. Accessed 20 Nov 2020.

11. Hazlehurst JM, Logue J, Parretti HM, et al. Developing integrated clinical pathways for the management of clinically severe adult obesity: a critique of NHS England Policy. Curr Obes Rep. 2020;9:530-43. https://doi.org/10.1007/s13679-020-00416-8.

12. Abbott S, Lawson J, Singhal R, et al. Weight loss during medical weight management does not predict weight loss after bariatric surgery: a retrospective cohort study. Surg Obes Relat Dis. 2020;16:1723-30. https://doi.org/10.1016/j.soard.2020.06.049.

13. Alkharaiji M, Anyanwagu U, Donnelly R, et al. Tier 3 specialist weight management service and pre-bariatric multicomponent weight management programmes for adults with obesity living in the UK: a systematic review. Endocrinol Diabetes Metab. 2019;2: e00042. https://doi.org/10.1002/edm2.42.

14. British Obesity and Metabolic Surgery Society. Patient access to bariatric surgery. 2017;3-8.

15. Ellis DA, McQueenie R, McConnachie A, et al. Demographic and practice factors predicting repeated non-attendance in primary care: a national retrospective cohort analysis. Lancet Public Heal. 2017;2:e551-9. https://doi.org/10.1016/S2468-2667(17)30217-7.

16. Charlton J, Rudisill C, Bhattarai N, et al. Impact of deprivation on occurrence, outcomes and health care costs of people with multiple morbidity. J Health Serv Res Policy. 2013;18:215-23. https://doi. org/10.1177/1355819613493772.

17. Brown TJ, O'Malley C, Blackshaw J, et al. Exploring the evidence base for tier 3 weight management interventions for adults: a systematic review. Clin Obes. 2017;7:260-72. https://doi.org/10.1111/ cob.12204.

18. Krimpuri RD, Yokley JM, Seeholzer EL, et al. Qualifying for bariatric surgery: is preoperative weight loss a reliable predictor of postoperative weight loss? Surg Obes Relat Dis. 2018;14:60-4. https://doi.org/10.1016/j.soard.2017.07.012.

19. Homer CV, Tod AM, Thompson AR, et al. Expectations and patients' experiences of obesity prior to bariatric surgery: a qualitative study. BMJ Open. 2016;6:1-10. https://doi.org/10.1136/bmjopen2015-009389.

Publisher's Note Springer Nature remains neutral with regard to jurisdictional claims in published maps and institutional affiliations. 